\title{
Mapping and modelling neglected tropical diseases and poverty in Latin America and the Caribbean
}

\author{
John B. Malone ${ }^{1}$, N. Robert Bergquist ${ }^{2}$ \\ ${ }^{1}$ Department of Pathobiological Sciences, School of Veterinary Medicine, Louisiana State University, Baton \\ Rouge, LA 70803, USA; ${ }^{2}$ Ingerod, Brastad, Sweden
}

\begin{abstract}
The prospects and opportunities for application of risk mapping and modelling of the neglected tropical diseases (NTDs) in Latin America are examined with the aim to broaden the interest in geospatial research there. Special reference is made to the potential use of geospatial tools in health planning and implementation of national disease control programmes.
\end{abstract}

Keywords: neglected tropical diseases, geospatial health, mapping, modelling, Latin America, Caribbean.

Geospatial technologies and neglected tropical diseases (NTDs)

The wider use of geographical information systems (GIS) and remote sensing became possible by the convergence of computer technology, Earth sciences and spatial statistics. The new vision was symbolized by the first Landsat satellite launched in 1972; its near 1 $\mathrm{km}^{2}$ resolution being a tantalizing harbinger of great things to come. Although access to these pictures was originally limited by high cost, one young student realized the possibilities on offer. Dr Barnett Cline published his idea over 40 years ago (Cline, 1970), followed later by an invited retrospect for the first issue of Geospatial Health (Cline, 2006). However, papers relying on satellite-based datasets did not begin to pick up until the 1980s when health-related research papers started to appear more regularly, partly explained by the reduced cost of remote sensing datasets. Today, however, GIS, remote sensing and global positioning systems (GPS) are well-known tools of the trade and few scientists working in the epidemiological field can manage without them.

Geospatial Health was first published six years ago as a forum for articles on health based on GIS and data capture from Earth-observing satellites. However, the intention was to also become a source of vital

Corresponding author:

John B. Malone

Department of Pathobiological Sciences

School of Veterinary Medicine

Louisiana State University

South Stadium Road Baton Rouge, LA 70803, USA

Tel. +1 225578 9671; Fax +1225 5789157

E-mail: malone@vetmed.lsu.edu information on the availability and use of the abovementioned technologies in medical and veterinary medicine, to promote geospatial monitoring techniques, to encourage studies of the potential impact of climate change, and to reveal the spatial and climatic parameters which determine the distribution limits of communicable diseases at various scales. These goals have largely been achieved (Utzinger at al., 2011) and we are now engaged in promoting novel ideas such as presentations in the form of mashups of video and text, introduced this year as a section of the journal under the banner of "vHealth" (visual health) (Bergquist and Tanner, 2012). This format is available in the online version of the journal (Krieger et al., 2012; Maire et al., 2012; Winkler et al., 2012).

Translational research, made possible by the expanding availability of medical mapping and modelling tools from the geospatial sciences, has now evolved from approaches requiring specialists in GIS and remote sensing technology to a level where it has become a normal part of health planning and implementation of national disease control programmes. Malaria and schistosomiasis, for example, are both environmentally sensitive, vector-borne diseases, which provide striking examples of the steady progress and increasing sophistication in the geospatial health arena (Cross et al., 1984; Bavia et al., 1999; Craig et al., 1999; Clements et al., 2006; Hay et al., 2009; Thomson et al., 2010; Zhou et al., 2010). In 1995, the NASA Ames Center for Health Applications of Aerospace Related Technologies (CHAART) was established by Byron Wood and Louisa Beck, who set about promoting applications in health by way of inhouse research, a small-grants programme and widely publicizing the medical potential of the new technolo- 
gies through symposia and workshops (Beck et al., 2000; Wood et al., 2000). Promising results had already been published on Rift Valley fever in Kenya by Linthicum et al. (1990) and the relationship of trypanosomiasis and its tsetse fly vectors to satellite imagery by Rodgers and Randolph (1991). Under the umbrella concept of "landscape epidemiology" initiated by Pavlovsky (1966), these early efforts were soon joined by other researchers (Galuzo, 1975; Kitron, 1998; Koch et al., 2007; Estrada-Peña, 2009; Anaruma Filho et al., 2010; Delgado-Petrocelli et al., 2011).

Our own organisation, the Global Network for Geospatial Health (www.gnosisGIS.org), was founded 12 years ago by a group of 10 scientists at a team residency at the Rockefeller Foundation Study and Conference Center in Bellagio, Italy. The proceedings were published in a special issue of Acta Tropica (Malone et al., 2001). The aim was to provide a vision and a forum for use of GIS, satellite-derived data and nationally funded digital databases on the environment produced by national and international agencies. Many of the methods and tools advocated were just emerging from the military sphere at the time and had been promptly applied in studies on agriculture, geography, Earth sciences and the environmental, but not yet widely adopted in the health field.

In 2002, the U.S. National Academy of Sciences published a report on the U.S. State Department's contribution to the Johannesburg World Summit on Sustainable Development, "Down to Earth Geographic Information for Sustainable Development in Africa" (NRC, 2002). It discussed early health related applications based on GIS and remote sensing, including malaria and schistosomiasis in East Africa and Egypt in the mid-1990s (Beck et al., 1994; Malone et al., 1994; Kitron et al., 1996). In the Americas, the Oswaldo Cruz Foundation (FIOCRUZ), the U.S. State Department and the Inter-American Institute for Global Change Research (www.iai.int) sponsored a workshop in 2003 in Rio de Janeiro, Brazil (Confaloneri and Marinho, 2005) that brought together representatives from Ministries of Health, academic researchers and remote sensing specialists to review progress on infectious disease control with emphasis on diseases endemic in the Americas and build a consensus on developing geospatial health capacity. Following this early work, rapid progress in the geospatial sciences provided medical scientists with better and less costly software, more widely available access to open-access mapping and modelling data, new GIS training opportunities and advanced spatial geostatistics. It is now commonplace to hear research reports and symposia at national and international meetings of medical societies referring to effective use of these tools. Thus, geospatial methodologies have become an integral part of epidemiology.

This special issue of Geospatial Health focuses on prospects and opportunities for application of geospatial health tools to the neglected tropical diseases (NTDs) in Latin America. The group of diseases constitutes a set of not uniquely defined infectious diseases. For example, the World Health Organization (WHO) lists 17 diseases from Buruli ulcer to yaws (http://www.who.int/neglected_diseases/diseases/en/), while the Global Network for Neglected Tropical Diseases highlights seven of the major infections of $90 \%$ of the world's poorest billion people and Hotez et al. (2009) mention 13 core NTDs in their seminal viewpoint article in the Lancet. These "diseases of poverty" afflict the world's most vulnerable populations and together they have a greater impact on global health than malaria or HIV/AIDS (Hotez, 2011). The NTDs dominate amongst poor people. Chagas, hookworm and other soil-transmitted helminth (STH) infections are the most important NTDs in the region but cysticercosis, leishmaniasis, lymphatic filariasis (LF), schistosomiasis and leprosy also play important roles in the public health area. With the exception of dengue, leprosy and leishmaniasis, the cause of these infections are all helminths and most of them require intermediate hosts or vectors to complete their life cycles. Although there is no vaccine or available chemotherapy for dengue fever and no safe and effective treatment against leishmaniasis, all other NTDs can be prevented and eliminated through the administration of inexpensive or donated medicines.

Various complexes of the NTDs exist in the different sub-regions of Latin America and the Caribbean, each with their own environmental ecology. The idea behind the current special issue of Geospatial Health is to broaden the interest in geospatial research pertaining to these diseases in Latin America and the Caribbean. We have previously published articles from Brazil and a few other countries in this region, but this time the geographical spectrum includes countries from Argentina in the south to Mexico in the north.

Invited articles authored by Ault and Colston provide insight into the perspectives of the Pan American Health Organization (PAHO) (Ault et al., 2012) and the Inter-American Development Bank (Colston, 2012) on NTDs in the Americas. Foley et al. (2012) and del Corral et al. (2012) add another perspective by addressing the use of essential open-access databases 
via the Internet. Following these are specific articles reporting on current studies on geospatial-related health issues in Latin America. Most contributions are based on oral presentations at the September 27-30, 2011 meeting of the Federation of Latin American Parasitologists in Bogota and the following $3^{\text {rd }}$ International Symposium on Geospatial Health, sponsored by GnosisGIS from September 30 to October 2, 2011 in Cartagena, Colombia. Several articles reported here result from a recent study on modelling NTDs and poverty in three countries in Latin America; Brazil, Colombia and Bolivia that was funded by the PAHO.

As pointed out by Mas-Coma et al. (1999), the epidemiological picture of fascioliasis has changed, and human infections caused by Fasciola can no longer be considered merely a secondary zoonotic aberration but must be considered an important human parasitic disease. Interestingly, a large number of papers in the presentations at the meetings mentioned above were focused on this disease, which is also reflected in this special issue (Martins et al., 2012; Rinaldi et al., 2012; Valencia-López et al., 2012). In addition, Fasciola infections figure prominently with regard to the role of landscape ecology in the acceleration of environmental and climate changes (Valencia-López et al., 2012), something also discussed with respect to malaria incidence in Venezuela by Delgado-Petrocelli et al. (2012), Chagas in Colombia (Mischler et al., 2012) and hookworm in Brazil (Mudenda et al., 2012).

In altogether different approach, a Mexican study published in this special issue concludes that the extrapolation of the metabolic syndrome (MetS) prevalence based on the body mass index (BMI) in a sample of the Mexican population reveals insights of general interest (Murgia-Romero et al., 2012). These authors show that $2.5 \%$ of all Mexicans suffer from MetS, that the syndrome is particularly pronounced in young people and that its geographical distribution is concentrated in the south (Yucatan) and in the north (Sonora State).

Schistosomiasis mansoni remains an important parasitic disease of man, endemic in large parts of subSaharan Africa, the Middle East, South America and the Caribbean. Two papers deal with this disease with emphasis on the snail intermediate host in Brazil. Both confirm that the presence of the snail is correlated to the disease (Barboza et al., 2012; Scholte et al., 2012). Of particular interest for the Brazilian distribution of the disease is the presence of two compatible species: Biomphalaria glabrata and B. straminea and that the competitive selection makes $B$. glabrata dominate in irrigation systems, while B. straminea is more common in natural water sources (Barboza et al., 2012).

In spite of the recent progress towards elimination of leprosy as a public health threat (http:// www.who.int/lep/) the disease remains a public health problem in many countries. In Brazil, the detection rate of new cases is 18.2 per 100,000 inhabitants and leprosy control is considered a priority in in many states. A significant association of males with the multi-bacillary form and neurological disability was observed in the state of Sergipe, Brazil, a predisposition that may be due to a delay in diagnosis and treatment (Teles de Olveira et al., 2012).

We have arrived at a threshold where integrated continental scale disease surveillance and health management systems are beginning to be implemented for diseases that are notorious for their low regard for national boundaries. There will be a special role for the geospatial health approach in control of these trans-boundary diseases as the same systems can be used for guiding the elimination of several "diseases of poverty". The article by Porcasi et al. (2012) in this special issue describes a comprehensive system for dengue control, currently implemented in Argentina, that may serve as a model for adoption on a wider scale. Mapping and modelling systems based on sound climate and environmental data that can be accessed in near-real-time to predict seasonal and inter-annual variations within the defined "normal" distribution range of a given disease agent. In the longer term, climate change models can be used to anticipate the widely held view that climate change may challenge control in the future. Particularly disturbing is the prediction that such change may not be gradual, but more precipitous and resistant to mitigation if recent concepts of "tipping points" in climate change becomes a reality (Lenton et al., 2008).

The membership of the Global Network for Geospatial Health intends to be counted among the advocates of the "landscape epidemiology" approach to controlling NTDs and other diseases. We propose that a mechanism is needed for guiding trans-boundary research groups, training programmes and implementation teams for NTDs within the hemisphere. By this special issue of Geospatial Health, we propose to add a voice to earlier calls to action advocated at the 2003 Rio de Janeiro conference of the InterAmerican Institute for Global Change Research and now promoted by current PAHO policy. Much progress has been made in research aimed at applying geospatial health solutions to disease problems in the Western Hemisphere, but progress is not yet 
comprehensive as translational research is only beginning to be applied in a practical way. Brazil's national information system for notifiable diseases (SINAN) is a notable example of an open-source national reportable disease surveillance system that may be integrated with compatible systems in this region to create trans-boundary disease surveillance systems that can be used with census block data to integrate socioeconomic drivers within dynamical NTD models.

\section{References}

Anaruma Filho F, Sant'Ana JM, dos Santos RF, Castagna CL, 2010. Environmental inducers of schistosomiasis mansoni in Campinas, Brazil. Geospat Health 5, 79-91.

Ault SK, Nicholls RS, Saboya MI, 2012. The Pan American Health Organization's role and perspectives on the mapping and modeling of Neglected Tropical Diseases in Latin America and the Caribbean: An overview. Geospat Health 6, S7-S9.

Beck LR, Rodriguez MH, Dister SW, Rodriguez AD, Rejmankova E, Ulloa A, Meza RA, Roberts DR, Paris JF, Spanner MA, Washino RK, Hacker C, Llewellyn J, Legters LJ, 1994. Remote sensing as a landscape epidemiologic tool to identify villages at high risk for malaria transmission. Am J Trop Med Hyg 51, 271-280.

Beck LR, Lobitz BM, Wood BL, 2000. Remote sensing and human health: new sensors and new opportunities. Emerg Infect Dis 6, 217-227.

Barboza DM, Zhang C, Santos NC, Silva MMBL, Rollemberg CVV, de Amorim FJR, Ueta MT, de Melo CM, de Almeida JAP, de Lourdes Sierpe Jeraldo V, Ribeiro de Jesus, A, 2012. Biomphalaria species distribution and its impact in human Schistosoma mansoni infection in an irrigated area used for rice cultivation in Northeast Brazil. Geospat Health 6, S103S109.

Bavia ME, Hale LF, Malone JB, Braud DH, Shane SM 1999. Geographic information systems and the Environmental Risk of Schistosomiasis in Bahia, Brazil. Am J Trop Med Hyg 60, 566-572.

Clements AC, Lwambo NJ, Blair L, Nyandindi U, Kaatano G, Kinung'hi S, Webster JP, Fenwick A, Brooker S, 2006. Bayesian spatial analysis and disease mapping: tools to enhance planning and implementation of a schistosomiasis control programme in Tanzania. Trop Med Int Health 11, 490-503.

Cline BL, 1970. New eyes for epidemiologists: aerial photography and other remote sensing techniques. Am J Epidemiol 92, 85-89.

Cline BL, 2006. Invited editorial for the inaugural issue of Geospatial Health. Geospat Health 1, 3-5.
Colston, J, 2012. The Interamerican Development Bank's Neglected Tropical Diseases Initiative for Latin America and the Caribbean and the role of geospatial analysis in health program. Geospat Health 6, S11-S14.

Confalonieri UEC, Marinho DP, 2005. Remote sensing and the control of infectious diseases: proceedings of an interamerican workshop. ENSP/FIOCRUZ, Rio de Janeiro, 104 pp.

Craig MH, Snow RW, le Sueur D, 1999. A climte based distribution model of malaria transmission in sub-Saharan Africa. Parasitol Today 15, 105-111.

Cross ER, Sheffield C, Perrine R, Pazzaglia G, 1984. Predicting areas endemic for schistosomiasis using weather variables and a Landsat data base. Mil Med 149, 542-544.

del Corral J, Blumenthal MB, Mantilla G, Ceccato P, Connor SJ, Thomson MC, 2012. Climate information for public health: the role of the IRI climate data library in an integrated knowledge system. Geospat Health 6, S15-S24.

Delgado-Petrocelli L, Camardiel A, Aguilar VH, Martinez N, Córdova K, Ramos S, 2011. Geospatial tools for the identification of a malaria corridor in Estado Sucre, a Venezuelan north-eastern state. Geospat Health 5, 169-176.

Delgado-Petrocelli L, Karenia C, Alberto C, Aguilar VH, Hernández D, Ramos S, 2012. Analysis of the El Niño/La Niña-Southern Oscillation (ENSO) variability and malaria in Estado Sucre, Venezuela. Geospat Health 6, S51-S57.

Estrada-Peña A, 2009. Diluting the dilution effect: a spatial Lyme model provides evidence for the importance of habitat fragmentation with regard to the risk of infection. Geospat Health 3, 143-155.

Foley DH, Wilkerson RC, Dornak LL, Pecor DB, Nyari, AS, Rueda LM. 2012. SandflyMap: leveraging spatial data on sand fly vector distribution for disease risk assessments. Geospat Health 6, S25-S30.

Galuzo IG, 1975. Landscape epidemiology (epizootiology). Adv Vet Sci Comp Med 19, 73-96.

Hay SI, Guerra CA, Gething PW, Patil AP, Tatem AJ, Noor AM, Kabaria CW, Manh BH, Elyazar IR, Brooker S, Smith DL, Moyeed RA, Snow RW, 2009. A world malaria map: Plasmodium falciparum endemicity in 2007. PLoS Med 6, e1000048.

Hotez P, 2011. Enlarging the "Audacious Goal": elimination of the world's high prevalence neglected tropical diseases. Vaccine 29, D104-110.

Hotez PJ, Bottazzi ME, Franco-Paredes C, Ault SK, Periago MR, 2008. The Neglected Tropical Diseases of Latin America and the Caribbean: a review of disease burden and distribution and a roadmap for control and elimination. PLoS Neglect Trop Dis 2, e300.

Kitron U, 1998. Landscape ecology and epidemiology of vectorborne diseases: tools for spatial analysis. J Med Entomol 35, 435-445.

Kitron U, Clennon JA, Cecere MC, Gürtler RE, King CH, 
Vazquez-Prokopec G, 1996. Upscale or downscale: applications of fine scale remotely sensed data to Chagas disease in Argentina and schistosomiasis in Kenya. Geospat Health1, 4958.

Krieger GR, Bouchard MA, Marques de Sa I, Paris I, Balge Z, Williams D, Singer BH, Winkler MS, Utzinger J, 2012. Enhancing impact: visualization of an integrated impact assessment strategy. Geospat Health 6, 303-306.

Koch DE, Mohler RL, Goodin DG, 2007. Stratifying land use/land cover for spatial analysis of disease ecology and risk: an example using object-based classification techniques. Geospat Health 2, 15-28.

Krieger GR, Bouchard MA, Marques de Sa I, Paris I, Balge Z, Williams D, Singer BH, Winkler MS, Utzinger J, 2012. Enhancing impact: visualization of an integrated impact assessment strategy. Geospat Health 6, 303-306.

Lenton TM, Held H, Kriegler E, Hall JW, Lucht W, Rahmstorf S, 2008. Tipping elements in the earth's climate system. Proc Natl Acad Sci USA 105, 1786-1793.

Linthicum KJ, Bailey CL, Tucker CJ, Mitchell KD, Logan TM, Davies FG, Kamau CW, Thande PC, Wagateh JN, 1990. Application of polar-orbiting, meteorological satellite data to detect flooding of Rift Valley Fever virus vector mosquito habitats in Kenya. Med Vet Entomol 4, 433-438.

Maire N, Hegnauer M, Nguyen D, Godelmann L, Hoffmann A, de Savigny D, Tanner M, 2012. The Health Resources Allocation Model (HRAM) for the 21st century. Geospat Health 6, 295-298.

Malone JB, Huh OK, Fehler DP, Wilson PA, Wilensky DE, Holmes RA, Elmagdoub AI, 1994. Temperature data from satellite imagery and the distribution of schistosomiasis in Egypt. Am J Trop Med Hyg 50, 714-722.

Malone JB, Bergquist NR, Huh OK, Bavia ME, Bernardi M, El Bahy MM, Fuentes MV, Kristensen TK, McCarroll JC, Yilma JM, Zhou XN, 2001. A global network for the control of snail-borne disease using satellite surveillance and geographic information systems. Acta Trop 79, 7-12.

Martins IVF, de Avelar BR, Pereira MJS, da Adevair HF, 2012. Application of a geographical information system (GIS) approach for risk analysis of fasciolosis in southern Espírito Santo state, Brazil. Geospat Health 6, S87-S93.

Mas-Coma MS, Esteban JG, Bargues MD, 1999. Epidemiology of human fascioliasis: a review and proposed new classification. Bull WHO 77, 340-245.

Mischler P, Kearney M, McCarroll J, Scholte RGC, Vounatsou P, Malone JB, 2012. Environmental and socioeconomic risk modeling for Chagas disease in Bolivia. Geospat Health 6, S59-S66.

Mudenda NB, Malone JB, Kearney MT, Mischler PD, del Mar
Nieto P, McCarroll JC, Vounatsou P, 2012. Modeling the ecological niche of hookworm in Brazil based on climate. Geospat Health 6, S111-S123.

Murguía-Romero M, Jiménez-Flores R, Villalobos-Molina R, Méndez-Cruz R, 2012. Estimating the geographic distribution of the prevalence of the metabolic syndrome in young Mexicans. Geospat Health 6, S43-S50.

Pavlovsky EN, 1966. Natural nidality of transmissible diseases, with special reference to the landscape epidemiology of zooanthroponse. University of Illinois Press, Urbana, IL, USA.

Porcasi X, Rotela CH, Introini MV, Frutos N, Lanfri S, Peralta G, De Elia EA, Lanfri MA, Scavuzzo CM, 2012. An operative dengue risk stratification system in Argentina based on geospatial technology. Geospat Health 6, S31-S42.

Rinaldi L, Gonzalez S, Guerrero J, Carol Aguilera LC, Musella V, Cringoli C, 2012. A One-Health integrated approach to control fascioliasis in the Cajamarca valley of Peru. Geospat Health 6, S67-S73.

Rogers DJ, Randolph SE, 1991. Mortality rates and population density of tsetse flies correlated with satellite imagery. Nature 351, 739-741.

Scholte RGC, Carvalho OS, Malone JB, Utzinger J, Vounatsou P, 2012. Spatial distribution of Biomphalaria spp, the intermediate host snails of Schistosoma mansoni in Brazil. Geospat Health 6, S95-S101.

Teles de Oliveira D, Bezerra MM, de Almeida JAP, Duthie M, Reed S, Ribeiro de Jesus A, 2012. Neurological disability in leprosy: incidence and gender association in Sergipe, Brazil. Geospat Health 6, S125-S129.

Thomson MC, Doblas-Reyes FJ, Mason SJ, Hagedorn R, Connor SJ, Phindela T, Morse AP, Palmer TN, 2006. Malaria early warnings based on seasonal climate forecasts from multimodel ensembles. Nature 439, 576-579.

Utzinger J, Rinaldi L, Malone JB, Krauth SJ, Kristensen TK, Cringoli G, Bergquist R, 2011. Geospatial Health: the first five years. Geospat Health 6, 137-154.

Valencia-López N, Malone JB, Velásquez LE, Carmona CG, 2012. Climate-based risk models for Fasciola hepatica in Colombia. Geospat Health 6, S75-S85.

Winkler MS, Krieger GR, Divall MJ, Singer BH, Utzinger J, 2012. Health impact assessment of industrial development projects: a spatio-temporal visualization. Geospat Health 6, 299-301.

Wood BL, Beck LR, Lobitz BM, Bobo MR, 2000. Education, outreach and the future of remote sensing in human health. Adv Parasit 47, 331-344

Zhou XN, Bergquist R, Leonardo L, Yang GJ, Yang K, Sudomo M, Olveda R, 2010. Schistosomiasis japonica control and research needs. Adv Parasitol 72, 145-178. 